\title{
A Green, Scalable, and Catalyst-Free One-Minute Synthesis of Quinoxalines
}

\author{
Vijayaragavan Elumalai \\ Jørn H. Hansen* (D)
}

UiT The Arctic University of Norway, Department of Chemistry, Chemical Synthesis and Analysis Division, Hansine Hansens veg 54, 9037 Tromsø, Norway

jorn.h.hansen@uit.no
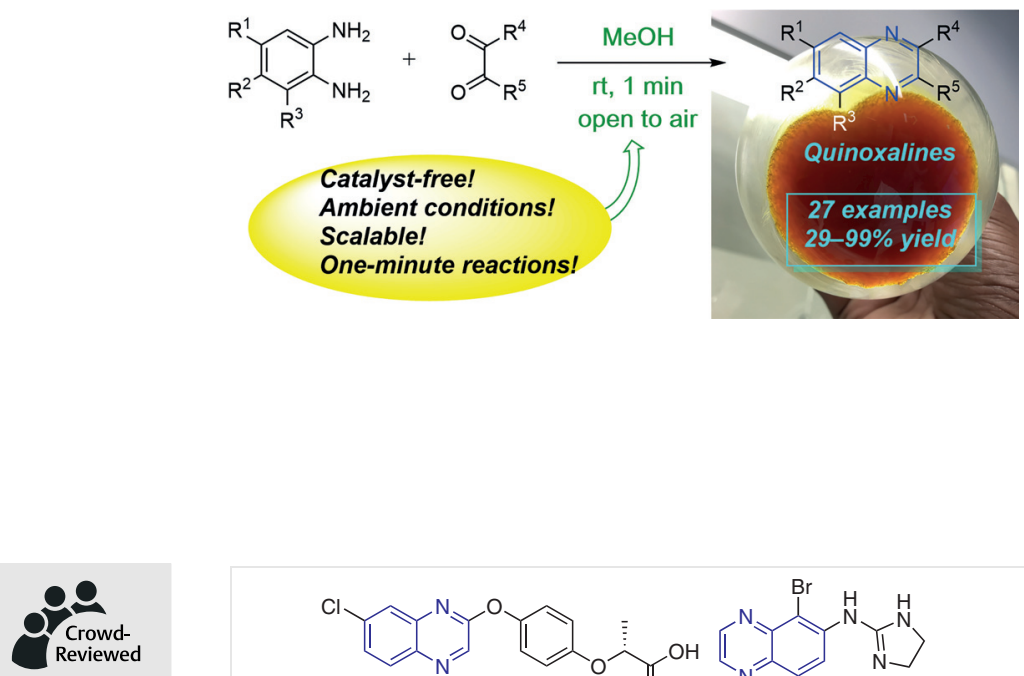

Received: 03.11.2020

Accepted after revision: 08.01.2021

Published online: 10.02 .2021

DOI: 10.1055/s-0040-1706021; Art ID: so-2020-d0041-I

Reviewed

License terms: $(9)(-)$

(c) 2021. The Author(s). This is an open access article published by Thieme under the terms of the Creative Commons Attribution-NonDerivative-NonCommercial-License, permitting copying and reproduction so long as the original work is given appropriate credit. Contents may not be used for commercial purposes or adapted, remixed, transformed or built upon. (https://creativecommons.org/licenses/by-nc-nd/4.0/)

Abstract A highly efficient and catalyst-free protocol is reported for the synthesis of quinoxalines via the classical cyclocondensation reaction between aryldiamines and dicarbonyl compounds. Remarkably simple and green reaction conditions employing methanol as solvent afforded medium to excellent yield of quinoxalines after only one-minute reaction time at ambient temperature. The conditions allow at least 10 gram scale synthesis of quinoxalines and should be a preferred starting point for optimization and method of choice for applications in the synthetic community.

Key words quinoxaline, diamine, condensation, diketone, green

Quinoxaline is one of the truly important nitrogen-containing heterocycles and versatile building blocks for the synthesis of natural products, pharmaceutical agents, ${ }^{1}$ and other biologically active compounds. ${ }^{2}$ The scaffold is linked with a number of pharmacological activities such as anticancer-,${ }^{3}$ antifungal-,${ }^{4}$ antiviral-,${ }^{5}$ antimalarial-,${ }^{6}$ antibacterial-, ${ }^{7}$ and immunosuppressive/antineoplastic activities ${ }^{8}$ (Figure 1). Moreover, the quinoxaline scaffold is also employed in a range of applications as dyes, ${ }^{9}$ organic semiconductors, ${ }^{10}$ anion receptors, ${ }^{11}$ dehydroannulenes, ${ }^{12}$ cavitands, ${ }^{13}$ electroluminescent materials, ${ }^{14}$ and DNA-cleaving agents. ${ }^{15}$ Quinoxalines are central components of several important antibiotics such as echinomycin, levomycin, and actinoleutin. ${ }^{16}$
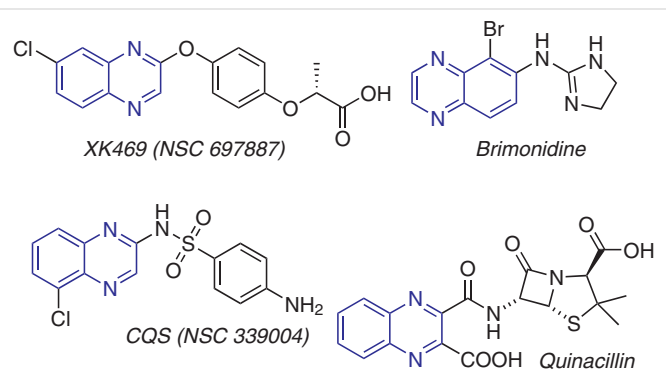

Figure 1 Some biologically important quinoxalines

The range of applications of quinoxalines has triggered the development of numerous synthetic methods for their synthesis. ${ }^{17}$ The direct condensation between 1,2-aryldiamines and 1,2-dicarbonyl compounds has been known since the late 1800s and is, arguably, one of the most widely known reactions in organic chemistry. ${ }^{17, \mathrm{~d}} \mathrm{~A}$ simple Scifinder search on the archetypical reaction between phenylenediamine and glyoxal reveals an astounding 48121 hits, truly underlining the power and widespread knowledge of this classical transformation. Some of the contemporary approaches towards quinoxalines also include the classical cyclocondensation and can be summarized as follows (Scheme 1): (a) the condensation reaction between diamines and dicarbonyl compounds under reflux in ethanol or acetonitrile with catalyst or acid present, ${ }^{18}$ (b) reaction between vicinal diols and diamines in the presence of variety of metal catalysts and strong bases, ${ }^{19}$ (c) reaction with $\alpha$-hydroxy ketones using $\mathrm{MnO}_{2}$ and $\mathrm{CuCl}_{2}$ as catalysts, ${ }^{20}$ and (d) the condensation of diamines with $\alpha$-halo ketones used for the synthesis of quinoxalines in the presence of TMSCl and $\mathrm{HClO}_{4}-\mathrm{SiO}_{2}$ as heterogeneous catalysts at elevated temperatures. ${ }^{21}$ 
Previous work

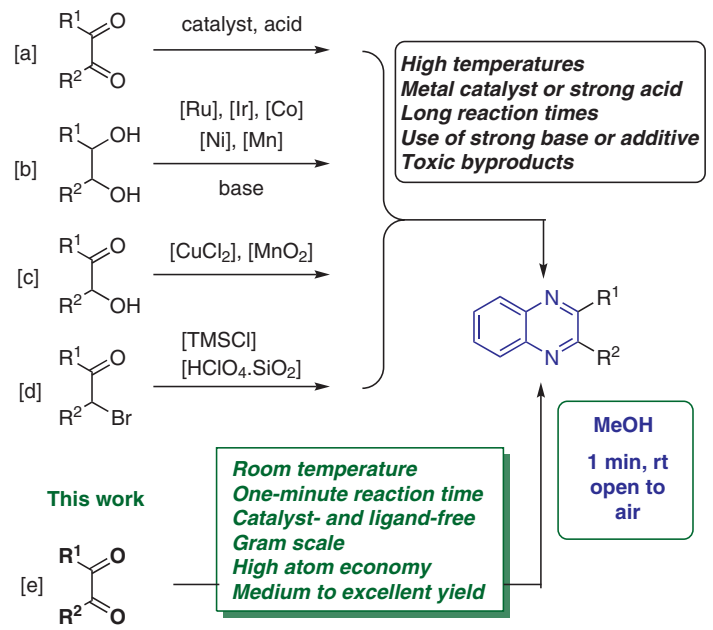

Scheme 1 Synthetic strategies for quinoxaline formation via phenylenediamines

There are several improvements in synthetic procedures reported using microwave irradiation, ${ }^{22}$ solid-phase synthesis, ${ }^{23}$ ultrasound, ${ }^{24}$ as well as solvent-free ${ }^{25}$ and roomtemperature conditions. ${ }^{25}$ Numerous catalyst systems have been reported for the synthesis of quinoxalines, including iodine, ${ }^{26}$ acetic acid, ${ }^{27}$ zeolites, ${ }^{28} \mathrm{Ni}$ nanoparticles, ${ }^{29}$ ionic liquids, ${ }^{30} \mathrm{NH}_{4} \mathrm{Cl}^{31} \mathrm{Al}_{2} \mathrm{O}_{3},{ }^{32} \mathrm{MnO}_{2},{ }^{33} \mathrm{POCl}_{3},{ }^{34} \mathrm{Pd}(\mathrm{OAc})_{2},{ }^{35}$ cerium ammonium nitrate, ${ }^{36}$ gallium triflate, ${ }^{37} \mathrm{CuSO}_{4} \cdot 5 \mathrm{H}_{2} \mathrm{O},{ }^{38}$ and sulfamic acid/methanol. ${ }^{39}$ In general, the reported methods often require elevated temperatures, strong acid catalyst, stoichiometric oxidant, expensive metal catalysts, or relatively long reaction times to facilitate the reaction with reasonable synthetic efficiency. Moreover, many of these methods typically display low-atom economy and yield undesirable byproducts. Thus, the development of highly efficient, simple, and environmentally benign reaction conditions is an important goal. In this regard, it can be noted that roughly half of the Scifinder hits on the reaction between phenylenediamine and glyoxal were classified as uncatalyzed, i.e., occurred with only heating and/or prolonged reaction times. In this myriad of reported conditions, it is difficult to navigate when considering the synthesis of a specific quinoxaline. In this paper, we intend to convey with clarity where to start.

It is often difficult to find a rationale for the use of all the different catalysts and additives that have been reported. However, it is well known that the condensation reaction can be catalyzed by Lewis or Brønsted acids. ${ }^{18,19}$ Moreover, the shear diversity and quantity of reaction conditions reported suggest that the condensation is very robust and tolerant. With this perspective, we have aimed to overcome typical limitations and to identify the most practical and simple reaction conditions for this classical transformation from which any optimization work should start. Herein, we demonstrate a very simple, high-yielding/highly atom-economic protocol for the synthesis of quinoxalines using diamines and dicarbonyl compounds in methanol as solvent at room temperature with only one-minute reaction time. To our surprise, previous accounts have not described the broad use and scope of the very simplest conditions for the synthesis of quinoxalines.

We have recently published a rapid method for the synthesis of benzimidazoles ${ }^{40}$ using only methanol as solvent at room temperature with one-minute reaction time. The unprecedented simplicity and efficiency of this system became the impetus for our current study, in which we investigate the synthesis of quinoxalines via 1,2-dicarbonyl compounds under similar experimental conditions. By mixing the reagents in $5 \mathrm{~mL} / \mathrm{mmol}$ methanol at room temperature for one minute in a vessel open to air, the reaction between phenylenediamine 1a and glyoxal 2a gave impressive 99\% GC conversion and $93 \%$ isolated yield of quinoxaline $\mathbf{3 a}$ (Table 1). ${ }^{41}$ The same reaction in ethanol also gave quantitative GC conversion, but somewhat less $85 \%$ isolated yield of $\mathbf{3 a}$. A survey of other solvents revealed that a broad spectrum of reaction media can be employed, and 99\% GC conversions were observed in acetonitrile, DMF, THF, ethyl acetate, and chloroform. There seems to be a consistent relation between the GC conversions and isolated yields.

Table 1 Solvent Screen for Quinoxaline Formation at One-Minute Reaction $^{\mathrm{a}}$

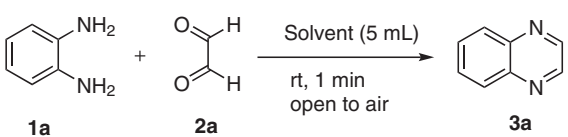

\begin{tabular}{lll}
\hline Entry & Solvent & Conversion $(\%)^{\mathrm{b}}$ \\
\hline 1 & acetone & 77 \\
2 & $\mathrm{H}_{2} \mathrm{O}$ & 60 \\
3 & $\mathrm{MeCN}$ & 99 \\
4 & $\mathrm{EtOH}$ & $99(85)^{\mathrm{c}}$ \\
5 & $\mathrm{MeOH}$ & $99(93)^{\mathrm{c}}$ \\
$6^{d}$ & $\mathrm{MeOH}^{\mathrm{d}}$ & $99(88)^{\mathrm{c}, \mathrm{d}}$ \\
7 & $\mathrm{DMF}^{\mathrm{d}}$ & 99 \\
8 & $\mathrm{THF}$ & 99 \\
9 & EtOAc & 99 \\
10 & $\mathrm{CHCl}_{3}$ & 99 \\
\hline
\end{tabular}

a Reaction procedure: to a stirred solution of diamine 1 (100 mg, 0.925 $\mathrm{mmol})$ in a specified solvent $(5 \mathrm{~mL})$, glyoxal $2(40 \%, 0.11 \mathrm{~mL}, 0.925 \mathrm{mmol})$ was added and stirred for $1 \mathrm{~min}$ at ambient temperature.

${ }^{\mathrm{b}} \mathrm{GC}$ conversion of starting material.

' Isolated yield.

d $\mathbf{1}, 10 \mathrm{~mL} \mathrm{mmol}^{-1}$ of solvent.

Only acetone and water gave lowered conversions in this assay (77\% and 60\%, respectively) which appeared to be due to solubility problems in these solvents. The reaction is 
relatively insensitive to the concentration, as a control experiment with doubled amount of methanol $\left(10 \mathrm{~mL} \mathrm{mmol}^{-}\right.$ ${ }^{1}$ ) afforded the same full conversion and an only slightly diminished isolated yield of $88 \%$ after one-minute reaction time. Thus, the amount of solvent employed can probably be minimized but $5 \mathrm{~mL} \mathrm{mmol}^{-1}$ was kept as standard for practical reasons. Based on this survey, the further studies were conducted in methanol although it should be noted that a range of solvents are viable.

We next studied various systems with different substituents on the diamine and the dicarbonyl components in order to ascertain the generality of the simple reaction conditions (Scheme 2). Adding methyl groups, using either butane-2,3-dione or 4,5-dimethylphenylenediamine or both as the electrophile, did not significantly alter the outcome of the corresponding condensation products 3a-d which were formed in excellent 93-96\% yields. Introducing halogens on the diamine, such as $\mathbf{3 k} \mathbf{1} \mathbf{l}$ led to diminished but still good yields (62-66\%). The 7-bromo-5-chloro-disubstituted product 3e was also formed in similar yield (65\%), whereas 6,7 -dichloroquinoxaline (3g) was formed in $40 \%$ yield. Further tests with butane-2,3-dione and the dihalogenated diamines also displayed diminished yields in this series (29$55 \%$ yields). Compound $3 \mathbf{f}$ was formed in the lowest yield (29\%) and even increasing the reaction time up to 30 minutes did not alter this outcome. The main problem appears to be that conversion of the starting material stops or becomes very slow (from GC analyses). The case of $\mathbf{3 g}$ was studied further to find a solution for improving the yields observed in the dihalogenated systems. Upon heating the reaction mixture in a microwave at $100{ }^{\circ} \mathrm{C}$ for 5 minutes, full conversion was observed, and $91 \%$ yield of $\mathbf{3 g}$ was isolated. Thus, heating is one effective solution, however, we were invested in finding as simple conditions as possible for rapid conversion into product. Conducting the reaction in acetic acid as solvent also gave full conversion of the starting material and $85 \%$ yield of $\mathbf{3 g}$ was isolated after one-minute reaction. This also suggests, not surprisingly, that the yield can be enhanced by acid catalysis, which was confirmed by an experiment in methanol adding $10 \mathrm{~mol} \%$ of acetic acid, which also gave full conversion and comparable $82 \%$ isolated yield of $\mathbf{3 g}$. The formation of product $\mathbf{3 f}$ was vastly improved to $98 \%$ yield upon microwave irradiation at $100{ }^{\circ} \mathrm{C}$ for 10 minutes. There seems to be several possible strategies for improving low-yielding cases while maintaining very short reaction times.

Interestingly, with butane-2,3-dione and monohalogenated diamines, the products $\mathbf{3} \mathbf{j}$ and $\mathbf{3} \mathbf{m}$ were formed in very high $87 \%$ and $98 \%$ yields, respectively. Moreover, the 6 cyanosubstituted system $\mathbf{3 n}$ was formed in $90 \%$ yield. A synergetic electronic combination may occur in these particular systems ensuring rapid transformations. Further, diaryl diketones were briefly explored, and $\mathbf{3 o}$ was formed in near quantitative yield. The dimethyl and monochloro systems 3p,q were also formed in excellent $91 \%$ and $89 \%$ yields,

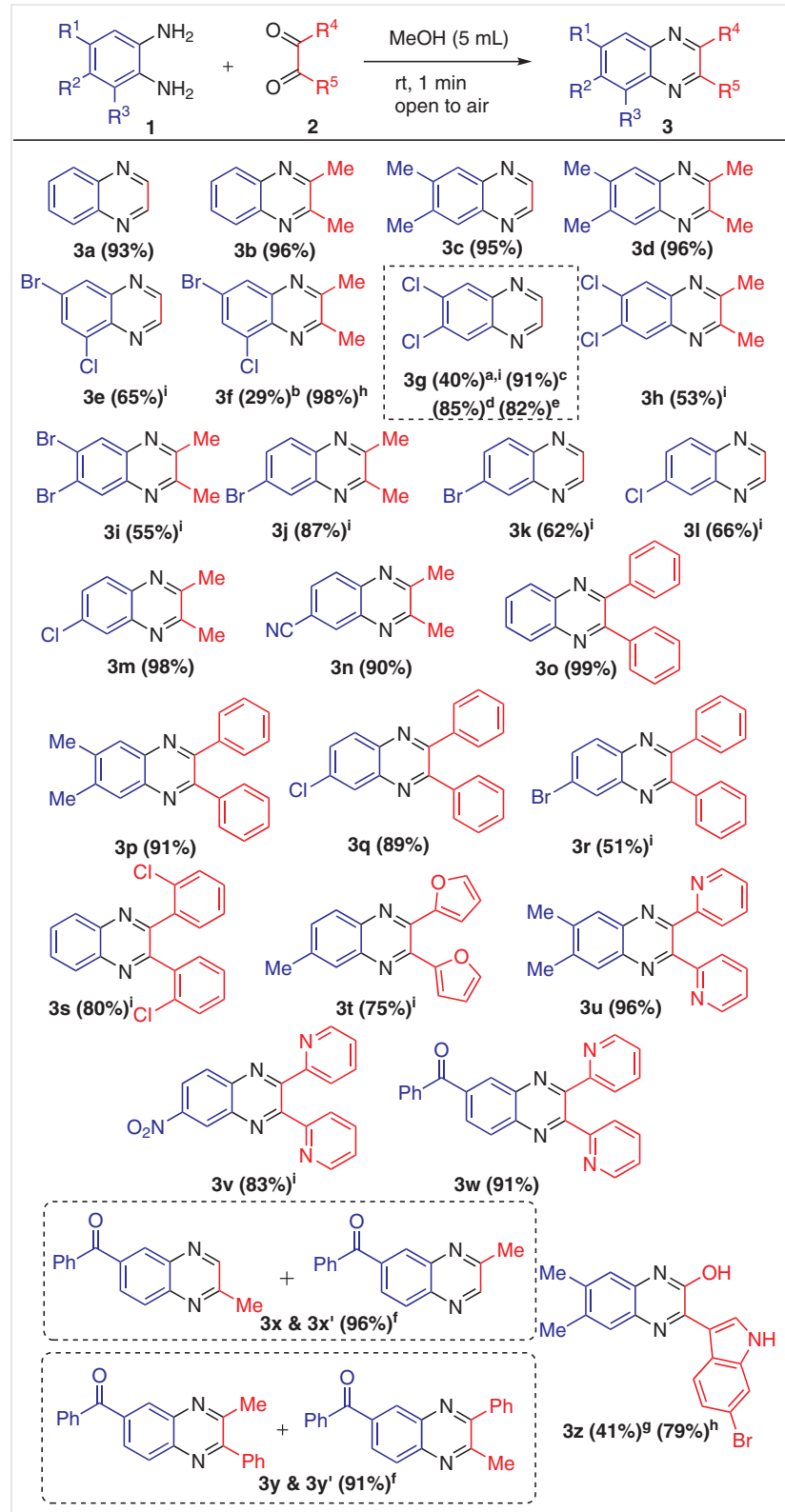

[a] Reaction Procedure: To a stirred solution of diamine $\mathbf{1}(0.925 \mathrm{mmol})$ in $\mathrm{MeOH}(5 \mathrm{~mL})$, dicarbonyl compound $\mathbf{2}(0.925 \mathrm{mmol})$ was added and stirred for one minute at ambient
temperature. Yields of crude material are reported for high-purity products, unless otherwise temperat.

[b] GC-yield. Similar GC-yield was obtained even with prolonged reaction time up to 30 minutes. [c] Reaction done at $100^{\circ} \mathrm{C}$ in microwave reactor for 5 mins. $99 \%$ GC-conversion was observed. [d] Reaction done at it in $\mathrm{AcOH}$ for one minute. $99 \%$ GC-conversion was observed.

[e] Reaction done at $\mathrm{rt}$ in $\mathrm{MeOH}$ with $10 \mathrm{~mol} \%$ of $\mathrm{AcOH}$ for one minute. $99 \% \mathrm{GC}$-conversion was observed.

[f] Mixture of isomers (1:1 ratio) was observed under the reaction conditions.

[g] NMR yield.

[h] Reaction done at $100^{\circ} \mathrm{C}$ in microwave reactor for $10 \mathrm{~min}$

[i] Isolated yield after flash column chromatography.

Scheme 2 Scope of the reaction between diamine 1 and dicarbonyl compounds 2

respectively, whereas the monobromo system yielded only moderate amounts of $\mathbf{3 r}$ (51\%). The chemistry is also compatible with substitution on the aryl diketone part, as the ortho-chlorosubstituted variant yielded $3 \mathrm{~s}$ in $80 \%$ isolated 
yield. There seems to be some tolerance towards sterically crowded electrophiles. Next, heteroaryl diketones were employed with 2-furyl and 2-pyridyl substituents. These worked excellently to generate fairly complex multiheteroaromatic systems 3t-w in $\mathbf{7 5 - 9 6 \% ~ y i e l d s . ~ F i n a l l y , ~ s o m e ~}$ unsymmetrical combinations were tested and 5-benzoylphenylenediamine in combination with 1,2-propanedione yielded excellent $96 \%$ of products $\mathbf{3 x} / \mathbf{3} \mathbf{x}^{\prime}$ as an equimolar isomeric mixture. An equimolar isomeric mixture was also observed with 1-phenyl-1,2-propanedione as electrophile, and $91 \%$ yield was isolated of $\mathbf{3 y}$ and $\mathbf{3} \mathbf{y}^{\prime}$. Lastly, 4,5-dimethylphenylenediamine was employed with indoyl-substituted oxocarboxylic acid $\mathbf{2 z}$ to generate the 2-hydroxy-3-(3-indoyl)-substituted quinoxaline $\mathbf{3 z}$ in moderate $41 \%$ yield (NMR). The yield was substantially improved upon microwave irradiation to $79 \%$. In this case, one of the electrophilic sites is a carboxylic acid, and the diminished electrophilicity is likely the reason for the attenuated reactivity. In general, all products appeared to be stable upon isolation and storage, so this cannot explain any diminished chemical yields. The compounds $\mathbf{3 f}$, $\mathbf{3 y}$, and $\mathbf{3 z}$ are novel molecules. ${ }^{42}$ Overall, the rapid quinoxaline formation appears to have rather broad scope with good to excellent yields obtainable in most cases and with temperature increase or simple acid catalysis as strategies to boost yields in problematic cases.

Based on the results herein, and a comparison with many of the literature studies employing various catalysts, heating, and prolonged reaction times, it is tempting to conclude that many studies lack an important control experiment without added catalyst. Moreover, prolonged reaction times and the need for heating of simple substrates may even suggest that the 'catalysts' employed in some cases actually decrease the reaction rates. This could occur if a metal predominantly coordinates with one or both of the substrates and thus, would reduce the effective concentration of reacting species and require more time or energy to effect an acceptable reaction outcome.

Based on these considerations and the results in this paper, we would like to strongly advocate that synthetic studies of quinoxaline formation using the classical condensation reaction should commence with the simple conditions described herein and that any novel catalytic reactions should be compared directly to the 'uncatalyzed' counterpart to assess the true catalyst performance. Lastly, it should be widely known and intuitive for practicing synthetic chemists that this classical condensation reaction can occur in minutes and without addition of catalysts. This does not appear to be the case upon examination of the literature.

In order to demonstrate further the applicability of these reaction conditions, five examples were conducted in experiments on larger scales (Scheme 3). ${ }^{41}$ Compounds $\mathbf{3} \boldsymbol{\alpha}$, 3o, and 3w were generated in high to excellent yields ( $91 \%$, $70 \%$, and $94 \%$ respectively) at $1 \mathrm{~g}$ scale using the basic con- ditions and methanol as solvent. If the reaction solvent was ethyl acetate, this would streamline the workup considerably since removal of the reaction solvent becomes unnecessary. Thus, we conducted the reaction at $10 \mathrm{~g}$ scale in eth$\mathrm{yl}$ acetate and quinoxalines $\mathbf{3 a}$ and $\mathbf{3} \boldsymbol{\alpha}$ were readily isolated in impressive $93 \%$ and $85 \%$ yields, respectively. This study strongly suggests that this should be a method of choice for the construction of such structures on scale.

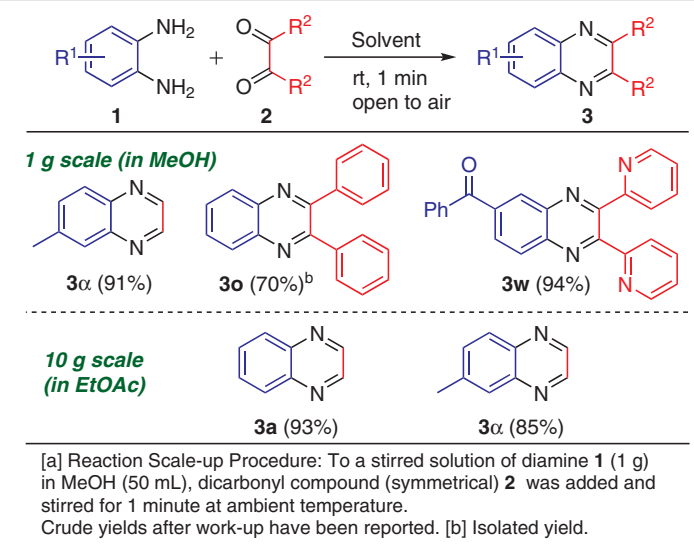

Scheme 3 Scale-up of the quinoxaline synthesis

In summary, we have revisited a classical transformation and report on improved synthesis efficiency and broadened scope of quinoxaline formation via the rapid condensation between aryldiamines and 1,2-dicarbonyl compounds. The cyclocondensation occurs fast under remarkably simple reaction conditions in medium to excellent chemical yields. Using methanol as solvent, the reaction typically proceeds at room temperature, open to air, and with only 1 minute reaction time. Problematic cases can be solved with simple acid catalysis or heating while maintaining very short reaction times. The practical nature and scalability of this green approach makes it an obvious starting point and method-of-choice for the synthesis of a range of quinoxalines.

\section{Funding Information}

Norges Forskningsråd (Research Council of Norway, Grant No. 275043 CasCat).

\section{Acknowledgment}

The authors wish to acknowledge the Department of Chemistry at UiT The Arctic University of Norway for staff support during this project.

\section{Supporting Information}

Supporting information for this article is available online at https://doi.org/10.1055/s-0040-1706021. 


\section{References and Notes}

(1) (a) Gazit, A.; App, H.; McMahon, G.; Chen, J.; Levitzki, A.; Bohmer, F. D. J. Med. Chem. 1996, 39, 2170. (b) Sehlstedt, U.; Aich, P.; Bergman, J.; Vallberg, H.; Norden, B.; Graslund, A. J. Mol. Biol. 1998, 278, 31.

(2) (a) Sakata, G.; Makino, K.; Kuraswa, Y. Heterocycles 1988, 27, 2481. (b) He, W.; Meyers, M. R.; Hanney, B.; Spada, A.; Blider, G.; Galzeinski, H.; Amin, D.; Needle, S.; Page, K.; Jayyosi, Z.; Perrone, H. Bioorg. Med. Chem. Lett. 2003, 13, 3097. (c) Kim, Y. B.; Kim, Y.H.; Park, J. Y.; Kim, S. K. Bioorg. Med. Chem. Lett. 2004, 14, 541.

(3) (a) Gao, H.; Huang, K.-C.; Yamasaki, E. F.; Chan, K. K.; Chohan, L.; Snapka, R. M. Proc. Natl. Acad. Sci. U.S.A. 1999, 96, 12168. (b) Cole, S. P.; Bhardwaj, G.; Gerlach, J. H. Science 1992, 258, 1650. (c) Lawrence, D. S.; Copper, J. E.; Smith, C. D. J. Med. Chem. 2001, 44, 594. (d) Yoo, H. W.; Suh, M. E.; Park, S. W.J. Med. Chem. 1998, 41, 4716. (e) Weng, Q.; Wang, D.; Guo, P. Eur.J. Pharmacol. 2008, 581, 262.

(4) (a) Tandon, V. K.; Yadav, D. B.; Maurya, H. K.; Chaturvedi, A. K.; Shukla, P. K. J. Med. Chem. 2006, 14, 6120. (b) Carta, A.; Loriga, M.; Paglietti, G. Eur. J. Med. Chem. 2004, 39, 195.

(5) (a) Fonseca, T.; Gigante, B.; Marques, M. M.; Gilchrist, T. L.; De Clercq, E. Bioorg. Med. Chem. 2004, 12, 103. (b) Ali, I.; AlMasoudi, I.; Hassan, H. G.; Al-Masoudi, N. Chem. Heterocycl. Compd. 2007, 43, 1052.

(6) (a) Crowther, A. F.; Curd, F. H.S.; Davey, D. G.; Stacey, G. J. J. Chem. Soc. 1949, 1260. (b) Rangisetty, J. B.; Gupta, C. N. V. H. B.; Prasad, A. L.; Srinivas, P.; Sridhar, N.; Parimoo, P.; Veeranjaneyulu, A. J. Pharm. Pharmacol. 2001, 53, 1409.

(7) (a) Kotharkar, S. A.; Shinde, D. B. Bioorg. Med. Chem. Lett. 2006, 16, 6181. (b) Mashevskaya, I. V.; Makhmudov, R. R.; Aleksandrova, G. A.; Golovnira, O. V.; Duvalov, A. V.; Maslivets, A. N. Pharm. Chem. J. 2001, 35, 196. (c) Vyas, D. A.; Chauhan, N. A.; Parikh, A. R. Indian J. Chem., Sect. B: Org. Chem. Incl. Med. Chem. 2007, 46, 1699.

(8) Gao, H.; Yamasaki, E. F.; Chan, K. K.; Shen, L. L.; Snapka, R. M. Cancer Res. 2000, 60, 5937.

(9) (a) Sonawane, N. D.; Rangnekar, D. W. J. Heterocycl. Chem. 2002, 39, 303. (b) Katoh, A.; Yoshida, T.; Ohkanda, J. Heterocycles 2000 , $52,911$.

(10) (a) Dailey, S.; Feast, W. J.; Peace, R. J.; Sage, I. C.; Till, S.; Wood, E. L. J. Mater. Chem. 2001, 11, 2238. (b) Brien, D.; Weaver, M. S.; Lidzey, D. G.; Bradley, D. D. C. Appl. Phys. Lett. 1996, 69, 881.

(11) Sessler, J. L.; Maeda, H.; Mizuno, T.; Lynch, V. M.; Furuta, H. Chem. Commun. 2002, 862.

(12) Ott, S.; Faust, R. Synlett 2004, 1509.

(13) (a) Sessler, J. L.; Maeda, H.; Mizuno, T.; Lynch, V. M.; Furuta, H. J. Am. Chem. Soc. 2002, 124, 13474. (b) Castro, P. P.; Zhao, G.; Masangkay, G. A.; Hernandez, C.; Gutierrez-Tunstad, L. M. Org. Lett. 2004, 6, 333.

(14) Thomas, K. R. J.; Velusamy, M.; Lin, J. T.; Chuen, C.-H.; Tao, Y.-T. Chem. Mater. 2005, 17, 1860.

(15) (a) Kazunobu, T.; Ryusuke, T.; Tomohiro, O.; Shuichi, M. Chem. Commun. 2002, 212. (b) Hegedus, L. S.; Greenberg, M. M.; Wendling, J. J.; Bullock, J. P. J. Org. Chem. 2003, 68, 4179.

(16) (a) Raw, S. A.; Wilfred, C. D.; Taylor, R. J. K. Org. Biomol. Chem. 2004, 2, 788. (b) Dell, A.; William, D. H.; Morris, H. R.; Smith, G. A.; Feeney, J.; Roberts, G. C. K. J. Am. Chem. Soc. 1975, 97, 2497. (c) Bailly, C.; Echepare, S.; Gago, F.; Waring, M. J. Anti-Cancer Drug Des. 1999, 15, 291.

(17) For some recent overviews, see: (a) Abu-Hashem, A. A. Am. J. Org. Chem. 2015, 5, 14. (b) Mamedov, V. A. In Quinoxalines 2016; 5 . For some historical references to the imine formation reac- tion, see: (c) von Pechmann, H. Ber. Dtsch. Chem. Ges. 1888, 21, 1411. (d) Zincke, T.; Schmidt, M. Justus Liebigs Ann. Chem. 1895, 286, 43.

(18) (a) Brown, D. J. In The Chemistry of Heterocyclic Compounds, Quinoxalines, Suppl. II; Taylor, E. C., Ed.; Wiley: Hoboken, 2004. (b) More, S. V.; Sastry, M. N. V.; Yao, C.-F. Green Chem. 2006, 8, 91. (c) Ajaikumar, S.; Pandurangan, A. Appl. Catal., A 2009, 357, 184. (d) Liu, J.-Y.; Liu, J.; Wang, J.-D.; Jiao, D.-Q.; Liu, H.-W. Synth. Commun. 2010, 40, 2047. (e) Kumbhar, A.; Kamble, S.; Barge, M.; Rashinkar, G.; Salunkhe, R. Tetrahedron Lett. 2012, 53, 2756. (f) Kadam, H. K.; Khan, S.; Kunkalkar, R. A.; Tilve, S. G. Tetrahedron Lett. 2013, 54, 1003. (g) Arde, S. M.; Patil, A. D.; Mane, A. H.; Salokhe, P. R.; Salunkhe, R. S. Res. Chem. Intermed. 2020, 46, 5069. For an example of a reaction in refluxing methanol without other additives, see: (h) Rewcastle, G. W.; Denny, W. A.; Baguley, B. C. J. Med. Chem. 1987, 30, 843.

(19) (a) Cho, C. S.; Oh, S. G. Tetrahedron Lett. 2006, 47, 5633. (b) Bera, A.; Sk, M.; Singh, K.; Banerjee, D. Chem. Commun. 2019, 55, 5958. (c) Daw, P.; Kumar, A.; Espinosa-Jalapa, N. A.; Posner, Y. D.; David, Y. B.; Milstein, D. ACS Catal. 2018, 8, 7734. (d) Shee, S.; Ganguli, K.; Jana, K.; Kundu, S. Chem. Commun. 2018, 54, 6883. (e) Hille, T.; Irrgang, T.; Kempe, R. Chem. Eur. J. 2014, 20, 5569. (f) Mondal, A.; Sahoo, M. K.; Subaramanian, M.; Balaraman, E. J. Org. Chem. 2020, 85, 7181.

(20) (a) Raw, S. A.; Wilfred, C. D.; Taylor, R. J. K. Chem. Commun. 2003, 2286. (b) Raw, S. A.; Wilfred, C. D.; Taylor, R. J. K. Org. Biomol. Chem. 2004, 2, 788. (c) Kim, S. Y.; Park, K. H.; Chung, Y. K. Chem. Commun. 2005, 1321. (d) Cho, C. S.; Oh, S. G. J. Mol. Catal. A.: Chem. 2007, 276, 205.

(21) Das, B.; Venkateswarlu, K.; Suneel, K.; Majhi, A. Tetrahedron Lett. 2007, 48, 5371.

(22) (a) Wan, J. P.; Gan, S.-F.; Wu, J.-M.; Pan, Y.-J. Green Chem. 2009, 11, 1633. (b) Villemin, D.; Martin, B. Synth. Commun. 1995, 25 , 2319. (c) Juncai, F.; Yang, L.; Qinghua, M.; Bin, L. Synth. Commun. 1998, 28, 193. (d) Vázquez, E.; De La Hoz, A.; Elander, N.; Moreno, A.; Stone-Elander, S. Heterocycles 2001, 55, 109. (e) Goswami, S.; Adak, A. K. Tetrahedron Lett. 2002, 43, 8371. (f) Zhao, Z.; Wisnoski, D. D.; Wolkenberg, S. E.; Leister, W. H.; Wang, Y.; Lindsley, C. W. Tetrahedron Lett. 2004, 45, 4873. (g) Kim, S. Y.; Park, K. H.; Chung, Y. K. Chem. Commun. 2005, 1321. (h) Kidwai, M.; Saxena, S.; Mohan, R. J. Korean Chem. Soc. 2005, 49, 288. (i) Azizian, J.; Karimi, A. R.; Kazemizadeh, Z.; Mohammadi, A. A.; Mohammadizadeh, M. R. Tetrahedron Lett. 2005, 46, 6155. (j) Gris, J.; Glisoni, R.; Fabian, L.; Fernández, B.; Moglioni, A. G. Tetrahedron Lett. 2008, 49, 1053.

(23) Wu, Z.; Ede, N. J. Tetrahedron Lett. 2001, 42, 8115.

(24) Sadjadi, S.; Sadjadi, S.; Hekmatshoar, R. Ultrason. Sonochem. 2010, 17, 764 .

(25) (a) Jafarpour, M.; Rezaeifard, A.; Danehchin, M. Appl. Catal. A 2011, 394, 48. (b) Zhou, J. F.; Gong, G. X.; Shi, K. B.; Zhi, S. J. Chin. Chem. Lett. 2009, 20, 672. (c) Krishnakumar, B.; Velmurugan, R.; Jothivel, S.; Swaminathan, M. Catal. Commun. 2010, 11, 997. (d) Niknam, K.; Saberi, D.; Mohagheghnejad, M. Molecules 2009, 14, 1915. (e) Darabi, H. R.; Mohandessi, S.; Aghapoor, K.; Mohsenzadeh, F. Catal. Commun. 2007, 8, 389.

(26) More, S. V.; Sastry, M. N. V.; Wang, C. C.; Ching-Fa, Y. Tetrahedron Lett. 2005, 46, 6345.

(27) Islami, M. R.; Hassani, Z. ARKIVOC 2008, (xv), 280.

(28) Bhosale, R. S.; Sarda, S. R.; Ardhapure, S. S.; Jadhav, W. N.; Bhusare, S. R.; Pawar, R. P. Tetrahedron Lett. 2005, 46, 7183.

(29) Kumar, A.; Kumar, S.; Saxena, A.; De, A.; Mozumdar, S. Catal. Commun. 2008, 9, 778 . 
(30) Dong, F.; Gong, K.; Fei, Z.; Zhou, X.; Liu, Z. Catal. Commun. 2008, 9, 317.

(31) Darabi, H. R.; Tahoori, F.; Aghapoor, K.; Taala, F.; Mohsenzadeh, F. J. Braz. Chem. Soc. 2008, 19, 1646.

(32) Jafarpour, M.; Rezaeifard, A.; Danehchin, M. Appl. Catal. A 2011, $394,48$.

(33) Raw, S. A.; Wilfred, C. D.; Taylor, R. J. K. Org. Biomol. Chem. 2004, $2,788$.

(34) Venkatesh, C.; Singh, B.; Mahata, P. K.; Ila, H.; Junjappa, H. Org. Lett. 2005, 7, 2169.

(35) Brown, D. J. Quinoxalines, In The Chemistry of Heterocyclic Compounds, Vol. 61; Taylor, E. C.; Wipf, P., Ed.; John Wiley \& Sons: Hoboken, 2004, 1.

(36) More, S. V.; Sastry, M. N. V.; Yao, C. F. Green Chem. 2006, 8, 91.

(37) Cai, J. J.; Zou, J. P.; Pan, X. Q.; Zhang, W. Tetrahedron Lett. 2008, 49, 7386.

(38) Heravi, M. M.; Taheri, S.; Bakhtiari, K.; Oskooie, H. A. Catal. Commun. 2007, 8, 211.

(39) Darabi, H. R.; Mohandessi, S.; Aghapoor, K.; Mohsenzadeh, F. Catal. Commun. 2007, 8, 389.

(40) Elumalai, V.; Hansen, J. H. Synlett 2020, 31, 547.

(41) Typical Procedure In a $25 \mathrm{~mL}$ round-bottom flask was added benzene-1,2-diamine (1a, $100 \mathrm{mg}, 0.925 \mathrm{mmol}$ ) which was dissolved in $\mathrm{MeOH}$ (5 mL). To the stirred solution, glyoxal (2a, 40\%, $134 \mathrm{mg}, 0.11 \mathrm{~mL}, 0.925$ mmol) was added and the mixture stirred for $1 \mathrm{~min}$ at ambient temperature, followed by quenching with water $(10 \mathrm{~mL})$, dilution with ethyl acetate $(50 \mathrm{~mL})$, and washing with water (30 $\mathrm{mL})$. The water layer was extracted with ethyl acetate $(2 \times 30$ $\mathrm{mL}$ ), the organic layers were combined, and dried over anhydrous $\mathrm{Na}_{2} \mathrm{SO}_{4}$. The drying agent was removed by filtration, and the solvent was evaporated under reduced pressure to obtain the desired product 3a as a yellowish liquid $(0.111 \mathrm{~g}, 93 \%)$ without column purification (GC purity $>99 \%)$. ${ }^{1} \mathrm{H}$ NMR $(400$ $\left.\mathrm{MHz}, \mathrm{CDCl}_{3}\right): \delta=8.84(\mathrm{~s}, 2 \mathrm{H}), 8.11(\mathrm{dd}, J=6.4,3.5 \mathrm{~Hz}, 2 \mathrm{H}), 7.78$ (dd, $J=6.4,3.5 \mathrm{~Hz}, 2 \mathrm{H}$ ). ${ }^{13} \mathrm{C}$ NMR $\left(101 \mathrm{MHz}, \mathrm{CDCl}_{3}\right): \delta=145.0$, 143.1, 130.1, 129.5.

\section{From 1-gram-scale Synthesis}

Compound 3w was obtained as golden-yellow solid (1.710 g, $94 \%$ ) without column purification (GC purity $>99 \%$ ). ${ }^{1} \mathrm{H}$ NMR (400 MHz, $\left.\mathrm{CDCl}_{3}\right): \delta=8.51(\mathrm{~d}, J=1.9 \mathrm{~Hz}, 1 \mathrm{H}), 8.33-8.21(\mathrm{~m}, 4$ $\mathrm{H}), 7.95(\mathrm{dt}, J=7.8,1.1 \mathrm{~Hz}, 1 \mathrm{H}), 7.89-7.80(\mathrm{~m}, 3 \mathrm{H}), 7.75(\mathrm{dtd}, J=$ 13.2, 7.7, $1.8 \mathrm{~Hz}, 2 \mathrm{H}), 7.60-7.51(\mathrm{~m}, 1 \mathrm{H}), 7.48-7.41(\mathrm{~m}, 2 \mathrm{H})$, 7.18 (dddd, $J=7.7,6.3,5.1,1.2 \mathrm{~Hz}, 2 \mathrm{H}) .{ }^{13} \mathrm{C}$ NMR $(101 \mathrm{MHz}$, $\left.\mathrm{CDCl}_{3}\right): \delta=195.7,157.1,157.0,154.1,153.6,148.7,148.7,142.9$, $140.2,138.8,137.1,136.8,136.8,132.9,132.5,130.4,130.2$, 129.9, 128.6, 124.4, 124.2, 123.4, 123.3 .

(42) Although there are only 3 novel compounds produced in this study, we have provided the NMR spectra for all entries in order to demonstrate the purity of the products after the indicated procedure. These can be found in the Supporting Information. 